\title{
Morphological Practical Teaching Platform Improves the Outcome of Anatomy Laboratory Teaching
}

\author{
La Plataforma de Enseñanza Práctica Morfológica Mejora el \\ Resultado de la Enseñanza de Laboratorio de Anatomía
}

\author{
Xiaoqing Liu ${ }^{1,2}$; Xiaoxian Shang'; Xuguang Wang'; Fengcang Zhou ${ }^{1}$ \\ Marco Lequio $^{3,4}$; Noah Signaigo ${ }^{3,4}$; Yujiang Fang ${ }^{3,4}$ \& Xiaojie Chen ${ }^{1}$
}

LIU, X.; SHANG, X.; WANG, X.; ZHOU, F.; LEQUIO, M.; SIGNAIGO, N.; FANG, Y. \& CHEN, X. Morphological practical teaching platform improves the outcome of anatomy laboratory teaching. Int. J. Morphol., 39(5):1395-1398, 2021.

SUMMARY: To investigate if the new morphological practice teaching platform could improve the outcome of anatomy laboratory teaching. Students were randomly divided into two groups taught with two different teaching methods. The two teaching methods used in this study were the traditional teaching model and the innovative teaching model. The teaching outcome including learning satisfaction between the two groups were studied. Both the teaching results and the teaching satisfaction of students in the integrated innovation teaching group were significantly higher than those in the control group. $(\mathrm{P}<0.05)$ This suggests that the new morphological practical teaching platform improves the outcome of anatomy laboratory teaching.

KEY WORDS: Anatomy; Teaching platform; Experimental teaching.

\section{INTRODUCTION}

Anatomy is one of the most important subjects in all medical schools. There are some problems with traditional teaching methods. For example, the content is boring or hard to remember. To adapt to the training plan of medical education under the new situation, the morphology teaching laboratory (Teaching Platform) has been applied and used for teaching. One old saying: "seeing is believing." Based on this saying, the construction of this laboratory provides a more intuitive learning environment for teachers' teaching and students' learning. The integrated and innovative teaching model allows for the structure and composition of the human body to be easily understood, touched, and remembered. In this paper, we tried to reform the experimental teaching model according to the use of experimental teaching and feedback by making full use of this teaching resource. Finally, we hope to provide some ideas and theoretical basis for the innovation of the anatomy experimental teaching mode.

\section{MATERIAL AND METHOD}

Research object. In this study, students majoring in acupuncture and massage were randomly divided into a control group and an experimental group. There were 108 cases in the control group, 46 males and 62 females, aged 18-26 years, with an average of $(19.94 \pm 1.09)$ years. There were 103 cases in the experimental group, 41 males and 62 females, aged 18-25 years, with an average of $(19.97 \pm 1.07)$ years old. There was no significant age difference between the two groups. $(\mathrm{P}>0.05)$

Implementation plan. In the control group, the conventional teaching model was adopted. According to the conventional teaching content, the teachers used PowerPoint pictures, anatomical molds, and/or wall charts combined with the textbook content to carry out the traditional teaching. In the teaching process of the experimental group, the teaching material "human morphology guidance" was used to assist in the teaching. The teaching was carried out according to

\footnotetext{
${ }^{1}$ Anthropotomy Teaching and Research Office, Anhui College of Traditional Chinese Medicine, Wuhu,Anhui, China 241000

${ }^{2}$ Department of Anatomy, Division of Life Sciences and Medicine, University of Science and Technology of China, Hefei, Anhui, China 230026

${ }^{3}$ Department of Microbiology, Immunology and Pathology, Des Moines University, Des Moines, IA, 50312, USA.

${ }^{4}$ Department of Surgery, University of Missouri School of Medicine, Columbia, MO, 65212, USA.

FUNDING: A major teaching and research project in Anhui Province (No. 2017jyxm0613).
} 
the syllabus and the integrated teaching content. This paper mainly lists the following three aspects of the implementation plan.

It enriches morphological resources and lays the foundation for subject integration through specimen construction. With the development of medical education, the unitary teaching model can no longer meet it. However, subject integration, a new basic medical teaching model, has provided new ideas for medical education (Zhang et al., 2014). Our school has been committed to nurturing applied technique-oriented medical professionals and vigorously updating teaching models for every subject through unremitting efforts and investigations. With great investments in specimen construction, Teaching Platform (Zhao et al., 2013) has currently included many morphological teaching specimens including anthroponomy, embryology, and pathology. There are cast specimens, sectional specimens, acupuncture indication specimens, etc. Traditional anatomy experimental teaching mainly focuses on specimens of normal humans. However, with the introduction of pathology and acupuncture indication, we start applying comparative observation methods of integrating different specimens to anatomic experimental teaching. For example, the pathology of fatty liver and liver cirrhosis are presented concurrently in liver teaching. Students observe and record related data: size, texture, color, and weight. Teachers reach conclusions based on the anatomic features of a living liver. Such an attempt leads to the differentiation between normal and abnormal and is not only favorable for understanding and memorizing, but also underlies the foundation for subsequent learning.

Acupuncture points specimen that highlights Chinese medical features leads to the reform of anatomy experimental teaching. The Teaching Platform (Zhao et al.) is an important part of the morphological laboratory, an optimal choice for learning the human body, and a significant place for students to test theoretical knowledge. In relation to the anatomy experimental teaching reform of massage and acupuncture, traditional anatomy teaching is neither tailored to different specialties with less satisfactory teaching performance nor adjusts the changes of the medical model. This affects the cultivation of applied technique-oriented medical professionals. It is an important basic medical course introducing clinical knowledge to meet the demand for integrating teaching resources and conducting anatomy experimental teaching reform. Bony landmarks of anatomic motor systems, surface projection of some key internal organs of splanchnology, important vessels, and nerve paths are the focus for students to learn anatomy. We take a whole specimen with acupuncture needles and sectional specimens so that students have an overall observation. Meanwhile, students are locating acupuncture points through anatomical landmarks of living organisms. In this way, students see different layers of different acupuncture points via sectional specimen and they are told to focus on where different parts, angles, and depth of acupuncturing lead to damage.

\section{Digitalized morphological practical teaching platform} greatly enriches anatomy experimental teaching methods. Medical information and digitized teaching models will lead to future reform of medical teaching. With the widespread application of IT, we have autonomously developed an anthroponomy video display system and database specimen inquiry system based on teaching needs and collected specimens. The system is managed by anatomy teachers who cooperate with experimental teachers based on the major organ system as a unit. Anatomizing and giving video display closeups of key and difficult points are an important part of the morphological teaching platform. They accomplish this by taking photos, naming, marking, locating, and remarking collected specimens. We have established a database specimen inquiry system with a simple interface and operation. Previous experimental teaching videos were purchased. As we continue to build and improve this teaching platform, students can get access to our self-developed video display. Specimens are also displayed in the Teaching Platform (Zhao et al.). This way, students can be involved in a real situation, enabling them to observe and verify normal body structure from multiple angles. Students can also know the location of specimens, that can be observed by entering keywords in the database specimen inquiry system. Additionally, students can see photos and images that are in line with the real ones to improve learning efficiency (Zhao et al.).

Statistical analysis. In this study, Prism was used for statistical analysis. Data was shown as mean \pm standard deviation ( $x \pm \mathrm{s}$ ). Chi-square test and T-test were used to detect the differences between the control and improved groups. $\mathrm{P}<0.05$ was defined as the statistical significance.

\section{RESULTS}

Results of two groups of practical assessment. Performance assessment mainly involves before class (control: 80.74 \pm 7.65 , improved: $86.20 \pm 6.94$ ), in class (control: $80.51 \pm 7.84$, improved: $86.45 \pm 6.70$ ), after class (control:78.81 \pm 8.12 , improved:86.48 \pm 6.43 ), final quiz (control:79.39 \pm 8.44 , improved:85.93 \pm 6.58 ) and combination (control:79.63 \pm 5.26 , improved: $86.17 \pm 3.90$ ), and is scored according to the 100 points system. It showed that the scores of the experimental group were higher than that of the control group, the difference was statistically significant (Fig. 1, p <0.05). 
Feedback survey results of teaching satisfaction of two groups. Teaching satisfaction is measured by the scale. The main indicators include teaching content, teaching form, teaching effect, and the influence of follow-up courses. According to the comprehensive score, satisfaction is evaluated according to four grades: very satisfied, satisfied, generally satisfied, and dissatisfied. The results showed that the satisfaction of the experimental group was higher than that of the control group and the difference was statistically significant (Table I, $\mathrm{p}<0.05)$.

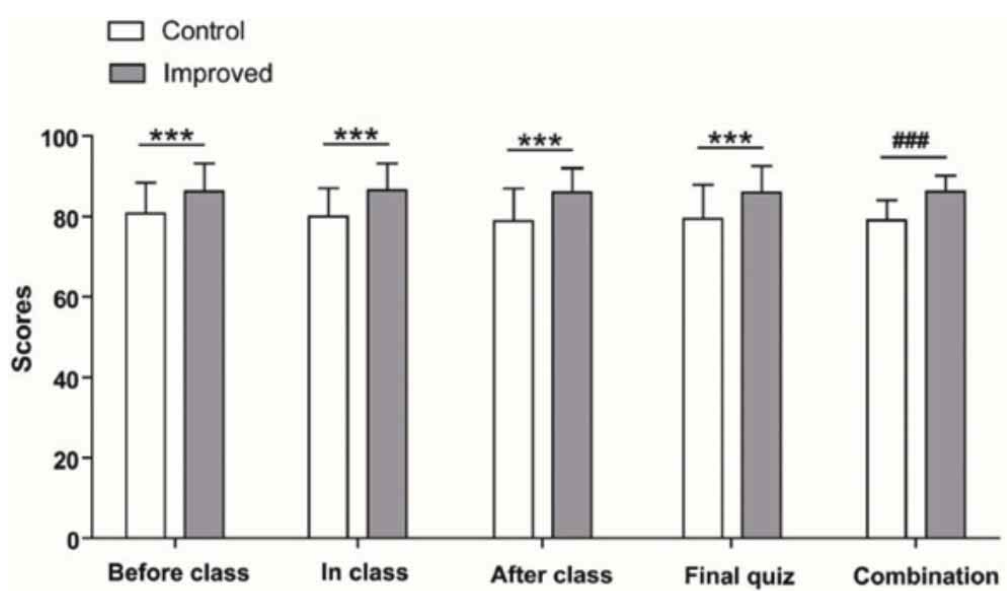

Combination $=0.1^{*}$ Before class $+0.2^{*}$ In class $+0.2^{*}$ After class $+0.5^{*}$ Final quiz

Fig. 1. Comparison between the different groups, the scores of the experimental group were higher than that of the control group, P?0. 05.

Table I. Comparison of teaching satisfaction between two groups.

\begin{tabular}{lcccccc}
\hline Groups & N & $\begin{array}{c}\text { Very } \\
\text { Satisfied }\end{array}$ & Satisfied & $\begin{array}{c}\text { General } \\
\text { Satisfied }\end{array}$ & Dissatisfied & $\begin{array}{c}\text { Satisfied } \\
\text { rate }\end{array}$ \\
\hline Improved & 103 & 34 & 50 & 17 & 2 & $98.06 \%$ \\
Control & 108 & 18 & 24 & 40 & 26 & $75.93 \%$ \\
\hline
\end{tabular}

Chi-squere Test, $\mathrm{P}<0.005$

\section{DISCUSSION}

Anatomy is a morphological science that is an important basic course of medicine and is not so easy to learn (Alzate-Mejia \& Tamayo-Alzate, 2019). The anatomical laboratory plays an important role for medical students to effectively learn anatomy (Rizzolo, 2002). How to carry out anatomy teaching and improve teaching effect, especially experiment teaching, is an eternal topic worth thinking about for every anatomy teacher (McMenamin, 2008; Lazarus et al., 2019). In the traditional teaching mode, teachers usually show students with samples and models, and students always acquire knowledge passively. The teaching materials are relatively old, so students can't transform their knowledge and apply it (Shi et al., 2019). The continuous improvement of the morphological practice teaching platform has brought great changes to the development of experimental teaching and the improvement of teaching effectiveness. The morphological practice teaching platform has allowed for anatomy to be easily learned and become interesting just like playing a game (Ang et al., 2018). In this study, the innovative morphological teaching model resulted in higher scores of practice assessments and the satisfaction of teaching in the experimental group than that of the control group. Some scholars have found that students' academic performance will be greatly improved after learning the integrated teaching content (Hinde, 2005). The analysis also demonstrates that the innovation of anatomic teaching, such as curriculum integration, platform establishment, and information mean (Liu et al., 2013), can greatly regulate students' interest in learning and improve students' satisfaction with teaching. Unfortunately, the students in this study are junior college students, with a short learning system and great employment pressure. There are not many graduate students engaged in this major. The longterm tracking sample of the teaching reform effect will be greatly reduced. In the form of teaching, it makes it more difficult for early guidance planning of student's careers.

Our new morphological practical teaching platform improves the outcome of anatomy laboratory teaching. This study might be helpful to reduce the stress of medical students in their anatomy study. In the future, we will further explore its potential functions by experimental assessment and evaluation of learning. Then we will try to contribute to the orderly and effective development of Anatomy Experimental Teaching under the new Teaching Platform

\section{ACKNOWLEDGEMENTS}

The authors wish to express their gratitude to all those who donated their bodies to medical science. 
LIU, X.; SHANG, X.; WANG, X.; ZHOU, F.; LEQUIO, M.; SIGNAIGO, N.; FANG, Y. \& CHEN, X. La plataforma de enseñanza práctica morfológica mejora el resultado de la enseñanza de laboratorio de anatomía. Int. J. Morphol., 39(5):1395-1398, 2021.

RESUMEN: El objetivo de este estudio fue investigar si la nueva plataforma de enseñanza práctica morfológica podría mejorar el resultado de la enseñanza en el laboratorio de anatomía. Los estudiantes se dividieron aleatoriamente en dos grupos utilizando dos métodos de enseñanza diferentes. Los métodos de enseñanza utilizados fueron el modelo de enseñanza tradicional y el modelo de enseñanza innovador. Se estudió el resultado de la enseñanza, como también la satisfacción con el aprendizaje entre los dos grupos. Tanto los resultados docentes como la satisfacción docente de los estudiantes del grupo de enseñanza de innovación integrada fueron significativamente superiores a los del grupo control $(\mathrm{p}<0,05)$. Esto sugiere que la nueva plataforma de enseñanza práctica morfológica mejora el resultado de la enseñanza del laboratorio de anatomía.

PALABRAS CLAVE: Anatomía; Plataforma de enseñanza; Enseñanza experimental.

\section{REFERENCES}

Alzate-Mejia, O. A. \& Tamayo-Alzate, O. E. Metacognition in the learning of anatomy. Int. J. Morphol., 37(1):7-11, 2019.

Ang, E. T.; Chan, J. M.; Gopal, V. \& Shia, N. L. Gamifying anatomy education. Clin. Anat., 31(7):997-1005, 2018.

Hinde, E. R. Revisiting curriculum integration: a fresh look at an old idea. Soc. Stud., 96(3):105-11, 2005.

Lazarus, L.; Sookrajh, R. \& Satyapal, K. S. Perceptions of South African academic instructors toward the teaching and learning of anatomy. Folia Morphol. (Warsz), 78(4):871-8, 2019.

Liu, W.; Liu, K.; Li, W. T.; Shen, X. H.; Chen, Y. M. \& Ma, C. H. Comparison of anatomy teaching between Yale University and Peking Union Medical College. Med. J. Peking Union Med. Coll. Hosp., 3:334-7, 2013.

McMenamin, P. G. Body painting as a tool in clinical anatomy teaching. Anat. Sci. Educ., 1(4):139-44, 2008.

Rizzolo, L. J. Human dissection: an approach to interweaving the traditional and humanistic goals of medical education. Anat. Rec., 269(6):242-8, 2002.

Shi, B. B.; Yang, H. M.; Zhang, X. \& Hao, Y. P. Traditional teaching mode and digital human technology application in anatomy teaching. Sci. Technol. Inf., 5:131-2, 2019.

Zhang, L.; Zhang, Z. X.; Wei, Q. \& Chen, X. M. Construction and practice research on comprehensive courses (anatomy, physiology and pathology) of nursing medicine in counterpart Vocational Colleges. Chin. J. Pract. Nurs., 2014(26):76-8, 2014.

Zhao, G. S.; Wu, M.; She, J. H. \& Wu, R. R. Practice and research on the construction of morphological practice teaching platform. Health Vocat. Educ., 2013(4):8-9, 2013.
Corresponding author:

Dr. Xiaojie Chen

Anthropotomy Teaching and Research Office

Anhui College of Traditional Chinese Medicine

Wuhu 241000

CHINA

Email:315263172@qq.com

Dr. Yujiang Fang, Department of Microbiology

Immunology and Pathology

Des Moines University

Des Moines, IA 50312

USA

E-mail: Yujiang.Fang@dmu.edu

Received: 29-05-2021

Accepted: 27-07-2021 